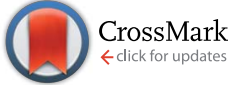

Cite this: Chem. Sci., 2016, 7, 3067

Received 10th November 2015 Accepted 26th January 2016

DOI: $10.1039 / \mathrm{c} 5 \mathrm{sc} 04293 \mathrm{c}$

www.rsc.org/chemicalscience

\title{
What determines if a ligand activates or passivates a superatom cluster? $\uparrow$
}

\author{
Zhixun Luo, ${ }^{* a b}$ Arthur C. Reber, ț $^{c}$ Meiye Jia, ${ }^{a}$ William H. Blades, ${ }^{c}$ Shiv N. Khanna*c \\ and A. W. Castleman, Jr. ${ }^{* b}$
}

Quantum confinement in small metal clusters leads to a bunching of states into electronic shells reminiscent of shells in atoms, enabling the classification of clusters as superatoms. The addition of ligands tunes the valence electron count of metal clusters and appears to serve as protecting groups preventing the etching of the metallic cores. Through a joint experimental and theoretical study of the reactivity of methanol with aluminum clusters ligated with iodine, we find that ligands enhance the stability of some clusters, however in some cases the electronegative ligand may perturb the charge density of the metallic core generating active sites that can lead to the etching of the cluster. The reactivity is driven by Lewis acid and Lewis base active sites that form through the selective positioning of the iodine and the structure of the aluminum core. This study enriches the general knowledge on clusters including offering insight into the stability of ligand protected clusters synthesized via wet chemistry.

\section{Introduction}

Considerable research over the past three decades has shown that small clusters containing a few to a few hundred atoms exhibit novel properties that change non-monotonically with size and shape, offering the prospect for better functional materials. ${ }^{1,2}$ Studies in cluster physics and cluster chemistry also provide information on the evolution in behaviour from the atomic scale to the solid state. The quantum states in small compact metal clusters group into shells that can be described within the confined Nearly Free Electron Gas (NFEG) model. ${ }^{3-9}$ The electronic states correspond to delocalized orbitals $1 \mathrm{~S}^{2}$, $1 \mathrm{P}^{6}, 1 \mathrm{D}^{10}, 2 \mathrm{~S}^{2} \ldots$ and when the valence electron count refers to a filled electronic shell, the cluster exhibits enhanced stability and reduced reactivity. The grouping of electronic states into shells and the associated stability and reactive patterns has enabled the description of clusters with well-defined valences as

${ }^{a}$ State Key Laboratory for Structural Chemistry of Unstable and Stable Species, Institute of Chemistry, Chinese Academy of Sciences, Beijing, 100190, China. E-mail: zxluo@iccas.ac.cn

${ }^{b}$ Departments of Chemistry and Physics, The Pennsylvania State University, University Park, PA 16802,USA. E-mail: awc@psu.edu

'Department of Physics, Virginia Commonwealth University, Richmond, VA 23284, USA. E-mail: snkhanna@vcu.edu

$\dagger$ Electronic supplementary information (ESI) available: Details of both experimental and theoretical (Fig. S1-S37), energies and reaction coordinates for the $\mathrm{Al}_{n} \mathrm{I}_{m}{ }^{-}$clusters, as well as coordinates for all these clusters. See DOI: 10.1039/c5sc04293c

\$ Z. Luo and A. C. Reber share the first authorship. superatoms forming a new dimension to the periodic table of elements.

In the gas phase, electronic shells explain cluster reactivity with oxygen, where magic clusters with electron counts corresponding to closed electronic shells like $\mathrm{Al}_{13}{ }^{-}$and $\mathrm{Al}_{23}{ }^{-}$etc. were found to be resistant towards oxygen etching. ${ }^{10-14}$ For example, the ground state of $\mathrm{Al}_{13}{ }^{-}$with 40 valence electrons corresponds to the filled shells of $\left|1 \mathrm{~S}^{2}\right| 1 \mathrm{P}^{6}\left|1 \mathrm{D}^{10} 2 \mathrm{~S}^{2}\right| 1 \mathrm{~F}^{14} 2 \mathrm{P}^{6} \mid$ with a HOMO-LUMO gap of $1.83 \mathrm{eV}$ to the $2 \mathrm{D}^{10}$ unfilled shell. The decrease in reactivity of these clusters with $\mathrm{O}_{2}$ is largely associated with the triplet ground state of $\mathrm{O}_{2}$ where the lowest unfilled orbitals are minority spin pi* orbitals. Any activation of the $\mathrm{O}_{2}$ molecule requires the filling of these minority $\mathrm{pi}^{*}$ orbitals which entails a spin excitation of the cluster to conserve the overall spin of the reactive complex. This activation energy is determined by the HOMO-LUMO gap and this explains why clusters with filled electronic shells and large HOMO-LUMO gaps are found to be unreactive towards $\mathrm{O}_{2}{ }^{15,16}$ Through studies on the oxygen etching of $\mathrm{Al}_{n}{ }^{-},{ }^{15} \mathrm{Mg}_{n} \mathrm{Al}_{m},{ }^{-13} \mathrm{CuAl}_{n}{ }^{-},{ }^{17} \mathrm{Al}_{n} \mathrm{H}_{m}{ }^{-18}$ $\mathrm{Al}_{n} \mathrm{C}^{-},{ }^{19}$ and $\mathrm{Al}_{n} \mathrm{~B}^{-}$clusters, ${ }^{20}$ it has been found that clusters with HOMO-LUMO gaps exceeding $1.2 \mathrm{eV}$ are all resistant to oxygen etching in flow tube experiments. Therefore, oxygen etching serves as a means to probe the filled electronic shells and the superatomic character of clusters., ${ }^{1,21}$ Since the valence electron count can be controlled by adding halogens, further studies on reactivity of $\mathrm{Al}_{n} \mathrm{I}_{m}{ }^{-}$clusters with oxygen showed that $\mathrm{Al}_{13} \mathrm{I}_{2 n}{ }^{-}$and $\mathrm{Al}_{14} \mathrm{I}_{2 n+1}{ }^{-}(n=$ integer $)$ clusters were resilient to reactivity with oxygen. ${ }^{22,23}$ These results allowed the classification of $\mathrm{Al}_{13}$ as a halogen superatom and $\mathrm{Al}_{14}$ as an alkaline earth superatom. 
Our studies on the reactivity of $\mathrm{Al}_{n}{ }^{-}$clusters with water, methanol and formaldehyde indicated that, unlike the case of atoms where a large HOMO-LUMO gap could lead to chemical inertness, the reactivity of superatoms with such polar molecules had a different fundamental origin. ${ }^{24-32}$ Species that have a non-uniform distribution of charge density are marked by Lewis acid sites that accept charge and Lewis base sites that donate charge. The Lewis acidity, rather than the charge acceptance, is most important because in the reaction with water and alcohols, the lone pair of the oxygen inserts into the aluminium cluster, so the cluster must accept an electron pair. The clusters with these complementary Lewis acid/base pairs are highly reactive with protic species. Thus, the chemical stability of a small metal cluster is maximized when, (i) the cluster has a closed electronic shell that corresponds to a HOMO-LUMO gap larger than $1.2 \mathrm{eV}$; and (ii) the charge density is evenly distributed over the surface of the cluster preventing the presence of active sites. These two criteria are also connected to other properties that correlate with reactivity such as higher ionization potentials, detachment energy and, as we show, reaction barriers.

Ligand protected metal clusters synthesized via wet chemistry have also generated extensive interest, and the stability of these ligated clusters are also explained using the superatom concept. ${ }^{33-38}$ Ligands such as thiols, phosphines and halides surrounding the noble metallic core are used to alter the electronic structure of the metal cluster leading to a delocalized electron count that corresponds to a filled electronic shell. These ligands are also used as passivating and protecting groups. ${ }^{35,37,39-43}$ For example, several aluminium cluster assembled materials have been synthesized including those based on $\mathrm{Al}_{77}$ and icosahedral $\mathrm{Al}_{12}$ motifs. ${ }^{44-46} \mathrm{Al}_{77}$ is particularly interesting as the cluster has a highly spherical shape and an odd number of electrons and does not have a closed electronic shell. ${ }^{46}$ Numerous ligand protected clusters have been synthesized by Schnöckel and co-workers revealing the rich chemistry of metalloids. ${ }^{\mathbf{4 7 8}}$ Irrespective of whether the cluster may be characterized as a metal or metalloid cluster, the fact that these clusters form materials implies that electronic shell closure is not the only criteria for material assembly. Also, as we have shown, the selective positioning of the ligands can be used to distort the charge density over the surface of the aluminium cluster resulting in active sites. ${ }^{28}$ The addition of a ligand can therefore protect a cluster enhancing stability or make it more reactive. The question is under what circumstances do ligands passivate or activate a superatom cluster?

We have identified two series of stable aluminium iodide clusters $\mathrm{Al}_{13} \mathrm{I}_{n}{ }^{-}(n=0,2,4)$ and $\mathrm{Al}_{14} \mathrm{I}_{m}{ }^{-}(m=3,5)$ by observing their stability in oxygen etching experiments. ${ }^{23}$ Here we clarify how ligands can be used to control the reactivity of metal clusters. We have performed a synergistic experimental and theoretical study of the etching of $\mathrm{Al}_{n} \mathrm{I}_{m}{ }^{-}$clusters with methanol. Due to its clean etching spectrum, and because its vapour pressure is higher than water, methanol was chosen as the etchant. The cluster reaction experiments were conducted in a fast flow reactor, and theoretical studies of the reactivity and active sites of $\mathrm{Al}_{n} \mathrm{I}_{m}{ }^{-}$were emphasized for $n=7-14$ and $m=0-2$.
We find that $\mathrm{Al}_{14} \mathrm{I}_{3}{ }^{-}$is reactive due to its activated adatom structure, where an aluminium atom with iodine lies on top of the icosahedral core. This activated adatom is found to serve as a Lewis acid site. In contrast, the $\mathrm{Al}_{13} \mathrm{I}_{m}{ }^{-}$clusters $(m=0-3)$ and $\mathrm{Al}_{7} \mathrm{I}_{2}{ }^{-}$are unreactive with methanol because of their symmetric core and their even distribution of charges around the surface of the cluster. Our findings not only explain the stability and reactivity of aluminium iodide clusters, but also provide new insight into the fundamental mechanism that prevent etching and the origin of stability in ligated-metal clusters.

\section{Materials and methods}

\section{Cluster production and reactivity}

The clusters were generated using a laser vaporization (LaVa) source, ${ }^{\mathbf{1 3}}$ made of stainless steel, with an external motor to control the target rotation of $\mathrm{Al}$ rod (Kurt J. Lesker, 99.999\% purity, $\Phi 6 \mathrm{~mm}$ ), as well as a gas inlet connection to a constant flow of helium (Praxair, Inc., purity $>99.995 \%$ ). Solid iodine (Sigma-Aldrich, 99.999\%) was added in the LaVa-source container to form aluminium iodide clusters. The outlet expansion nozzle was made of a Teflon tube $(\sim 2.5 \mathrm{~cm}$ length) with an inner diameter of $0.32 \mathrm{~cm}$. The pressure inside the source during operating conditions was kept at $\sim 20$ Torr, suggesting a Knudsen number of $\sim 2.8 \times 10^{-3}$ and a terminal Mach number of $\sim 12.3$. The helium buffer gas introduced from the inlet of the source carried the clusters through the nozzle into a flow tube where they encountered and reacted with methanol (Sigma-Aldrich, $>99.9 \%$ ) at room temperature. The reactant methanol gas was introduced in the cluster beam $\sim 30 \mathrm{~cm}$ downstream from the source (resulting in thermalized $\mathrm{Al}_{n} \mathrm{I}_{m}{ }^{-}$clusters) and allowed to react with the clusters over a $60 \mathrm{~cm}$ distance and time of $\sim 8 \mathrm{~ms}$. The reaction products were extracted into a differentially pumped ion guide vacuum system, and analysed via a quadrupole mass spectrometer (Extrel QMS). The pressure in the reaction flow-tube was kept at $\sim 0.7$ Torr, i.e., several hundred collisions for the related reactions.

\section{Computational methods}

Energy calculations of the ground state geometry, electronic structure, and transition state were carried out using a first principles density functional approach. The calculations used a linear combination of Slater type orbitals located at atomic sites using the Amsterdam density functional set of codes. ${ }^{49}$ They were carried out using the TZ2P basis within the PBE gradient corrected density functional formalism. ${ }^{50}$ The zeroth order regular approximation was used for relativistic effects. All structures were fully optimized without constraints. The transition states were calculated using the linear transit approach, by fixing the $\mathrm{O}-\mathrm{H}$ bond distance over a range of distances and identifying the saddle point.

\section{Results and discussion}

We have achieved a well-resolved mass spectrum of $\mathrm{Al}_{n} \mathrm{I}_{m}{ }^{-}(7<n$ $<37, m=0-3$ ) clusters by adding solid iodine into the LaVa 
source ( $\sim 20$ Torr pressures), as shown in Fig. 1A. The $\mathrm{Al}_{n} \mathrm{I}_{m}{ }^{-}$ clusters display a normal distribution centred at $\mathrm{Al}_{21}{ }^{-}$, except for $\mathrm{Al}_{13}{ }^{-}$which exhibits slightly enhanced stability. Aluminium readily reacts with iodine at room temperature and the formed aluminium iodides mainly cover $\mathrm{Al}_{n} \mathrm{I}_{1-3}{ }^{-}$, with $\mathrm{Al}_{13} \mathrm{I}^{-}$and $\mathrm{Al}_{13} \mathrm{I}_{2}{ }^{-}$as the most abundant. After the addition of methanol, the $\mathrm{Al}_{n} \mathrm{I}_{m}{ }^{-}$abundancies undergo a dramatic change due to etching, as shown in Fig. 1B (for more details see ESI, Fig. S1 and $\mathrm{S} 2 \dagger$ ). Peaks corresponding to $\mathrm{I}^{-}, \mathrm{I}_{3}{ }^{-}, \mathrm{AlI}_{4}{ }^{-}$, and $\mathrm{I}_{5}{ }^{-}$appear with enhanced intensities owing to the production of $\mathrm{I}^{-}$in the etching reactions. Most of the $\mathrm{Al}_{n} \mathrm{I}_{m}{ }^{-}$clusters with sizes larger than $n=13$ disappear or display weakened intensities. We note that $\mathrm{Al}_{13}{ }^{-}, \mathrm{Al}_{13} \mathrm{I}_{2}{ }^{-}$and $\mathrm{Al}_{13} \mathrm{I}_{4}{ }^{-}$(as marked with $\boldsymbol{\Delta}, \boldsymbol{\bullet}, \boldsymbol{\bullet}$ in Fig. 1) display analogous stability to $\mathrm{I}^{-}$and hypervalent $\mathrm{I}_{3}{ }^{-} / \mathrm{I}_{5}{ }^{-}$ respectively surviving the methanol etching reactions $\left(\mathrm{Al}_{13}{ }^{-} \leftrightarrow\right.$ $\mathrm{X}^{-} ; \mathrm{Al}_{13} \mathrm{I}_{2}{ }^{-} \leftrightarrow \mathrm{X}_{3}{ }^{-} ; \mathrm{Al}_{13} \mathrm{I}_{4}{ }^{-} \leftrightarrow \mathrm{X}_{5}{ }^{-}$).

Fig. 2A-C plot the intensities of $\mathrm{Al}_{n} \mathrm{I}_{0-2}{ }^{-}$clusters in the absence and presence of methanol. The intensities of $\mathrm{Al}_{7} \mathrm{I}^{-}$, $\mathrm{Al}_{8} \mathrm{I}^{-}, \mathrm{Al}_{8} \mathrm{I}_{2}{ }^{-}, \mathrm{Al}_{13}{ }^{-}, \mathrm{Al}_{13} \mathrm{I}_{2}{ }^{-}$and $\mathrm{Al}_{13} \mathrm{I}_{4}{ }^{-}$are strengthened up to twice of their nascent peaks. $\mathrm{Al}_{7} \mathrm{I}_{2}{ }^{-}, \mathrm{Al}_{20} \mathrm{I}^{-}, \mathrm{Al}_{13} \mathrm{I}^{-}$, and $\mathrm{Al}_{13} \mathrm{I}_{3}{ }^{-}$ (Fig. $\mathrm{S} 3 \dagger$ ) display similar intensities before and after methanol etching. $\mathrm{Al}_{13} \mathrm{I}^{-}$and $\mathrm{Al}_{13} \mathrm{I}_{3}{ }^{-}$have an odd number of electrons, confirming that a closed electronic shell is not necessary for a cluster to be resistant to methanol etching. $\mathrm{Al}_{14} \mathrm{I}_{3}{ }^{-}$was previously found to be resistant to oxygen etching, ${ }^{23}$ however the abundant $\mathrm{Al}_{14} \mathrm{I}_{3}{ }^{-}$is almost completely depleted after methanol is introduced to the flow tube. Seen from Fig. $2 \mathrm{~A}-\mathrm{C}, \mathrm{Al}_{7} \mathrm{I}^{-}$and $\mathrm{Al}_{7} \mathrm{I}_{2}{ }^{-}$have higher abundances after methanol etching, showing that the addition of iodine may sometimes activate a cluster.

To understand the microscopic mechanism by which these clusters react with methanol, we have investigated the lowest energy structures for $\mathrm{Al}_{n} \mathrm{I}_{0-2}{ }^{-}(n=7-14)$, and also $\mathrm{Al}_{9} \mathrm{I}_{3}{ }^{-}$and $\mathrm{Al}_{14} \mathrm{I}_{3}{ }^{-}$. Fig. $\mathrm{S} 4$ and $\mathrm{S} 5 \dagger$ show the structures, and Fig. S6 $\dagger$ shows the HOMO-LUMO gaps, aluminium and iodine binding energies. Several clusters have HOMO-LUMO gaps that are large enough that the cluster may be considered to have a closed electronic shell. For example, $\mathrm{Al}_{7} \mathrm{I}_{2}{ }^{-}$has a gap of $1.73 \mathrm{eV} ; \mathrm{Al}_{13}{ }^{-}$ and $\mathrm{Al}_{13} \mathrm{I}_{2}{ }^{-}$have gaps of $1.81 \mathrm{eV}$ and $1.59 \mathrm{eV}$ respectively, and $\mathrm{Al}_{14} \mathrm{I}_{3}{ }^{-}$has a gap of $1.35 \mathrm{eV}$. Previous studies have indicated that clusters with HOMO-LUMO gaps higher than $1.2 \mathrm{eV}$ are generally non-reactive towards oxygen. ${ }^{13-15}$ The electronic structure of $\mathrm{Al}_{13}{ }^{-}, \mathrm{Al}_{14} \mathrm{I}_{3}{ }^{-}$, and $\mathrm{Al}_{7} \mathrm{I}_{2}{ }^{-}$are shown in Fig. $\mathrm{S} 7 \dagger$ for reference. As pointed out in the introduction, these clusters are expected to be non-reactive with oxygen.

To understand the reactivity with methanol, we have calculated the lowest energy transition state for the breaking of the $\mathrm{O}-\mathrm{H}$ bond on the clusters surface of $\mathrm{Al}_{n}{ }^{-}, \mathrm{Al}_{n} \mathrm{I}^{-}$and $\mathrm{Al}_{n} \mathrm{I}_{2}{ }^{-}$ respectively. In our previous studies on $\mathrm{Al}_{n}{ }^{-}$clusters, we found that water and methanol only form complexes when the $\mathrm{O}-\mathrm{H}$ bond is broken. ${ }^{21-23}$ Fig. 2D displays the transition state energies, $E_{\mathrm{TS}}$, for the $\mathrm{Al}_{n}{ }^{-}$clusters. We have used the $E_{\mathrm{TS}}$, as shown in eqn (1), as a measure of the reactivity in the gas phase. The reaction may proceed rapidly when the $E_{\mathrm{TS}}$ is negative, and the reaction will proceed slowly when the $E_{\mathrm{TS}}$ is positive.

$$
E_{\mathrm{TS}}=E\left(\mathrm{Al}_{n} \mathrm{I}_{m}\left(\mathrm{CH}_{3} \mathrm{O}-\mathrm{H}\right)_{\mathrm{TS}}{ }^{-}\right)-E\left(\mathrm{CH}_{3} \mathrm{OH}\right)-E\left(\mathrm{Al}_{n} \mathrm{I}_{m}{ }^{-}\right)
$$

The $E_{\mathrm{TS}}$ is most applicable in gas phase reactions, because the energy gained by the adsorption of the reactant remains in the cluster. In solution, the activation energy, the energy difference between the methanol-cluster complex and the transition state, will be more important. This is due to the fact that the energy gained by complex formation is more rapidly dissipated into the surrounding environment. Another way to consider this is, if the energy required to cleave the $\mathrm{O}-\mathrm{H}$ bond is lower than the energy required for desorption of the molecule, then we expect $\mathrm{O}-\mathrm{H}$ cleavage to be a likely product, and when

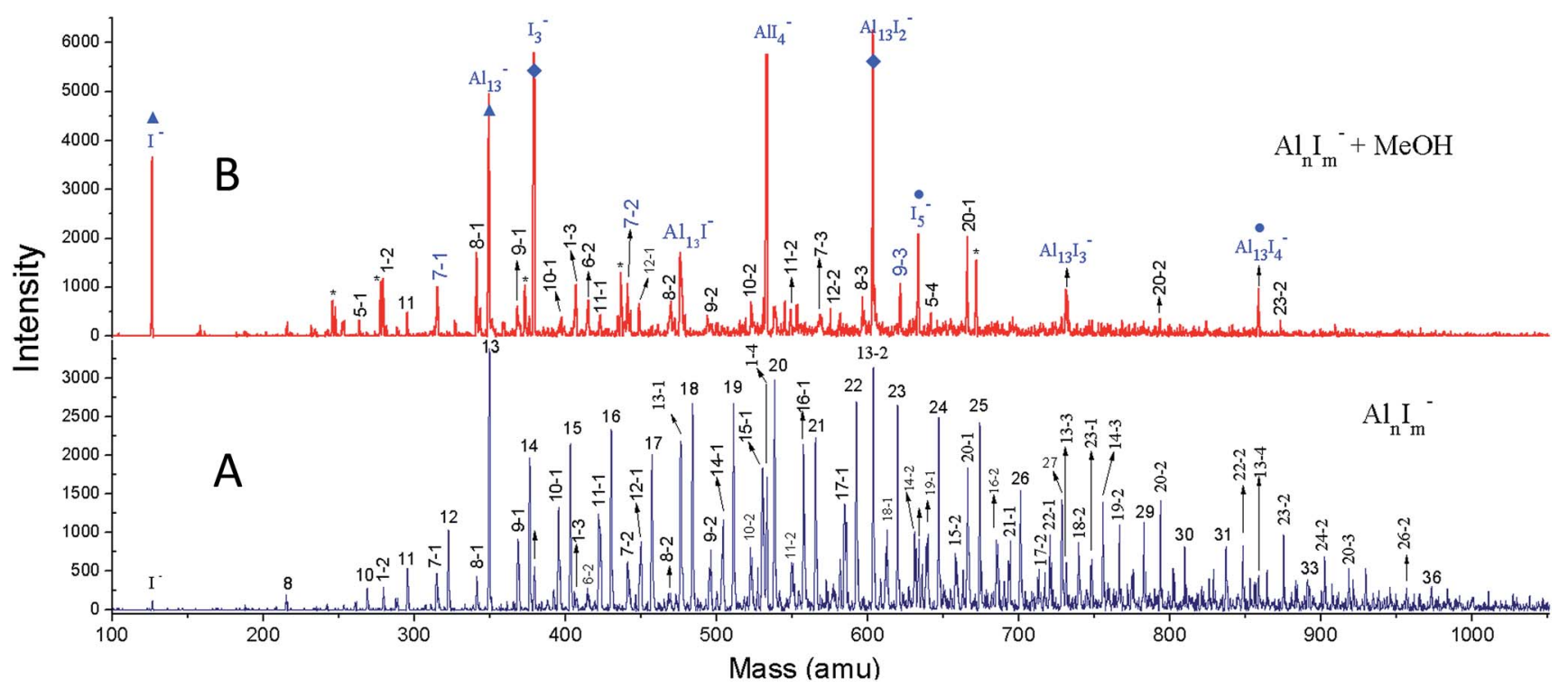

Fig. 1 The reactivity of $\mathrm{Al}_{n} \mathrm{I}_{m}{ }^{-}$clusters with $\mathrm{MeOH}$. (A) The nascent mass spectrum of $\mathrm{Al}_{n} \mathrm{I}_{m}{ }^{-}{ }^{-}$clusters. (B) The spectrum of $A l_{n} \mathrm{I}_{m}{ }^{-}{ }^{-} \mathrm{clusters}$ after methanol etching. A few peaks marked with * refer to $\mathrm{Al}_{n}\left(\mathrm{CH}_{3} \mathrm{OH}\right)_{m}{ }^{-}$; while the peaks marked with $\boldsymbol{\Lambda}$, and $\mathrm{Al}_{13} \mathrm{I}_{4}{ }^{-}$species respectively. 
A
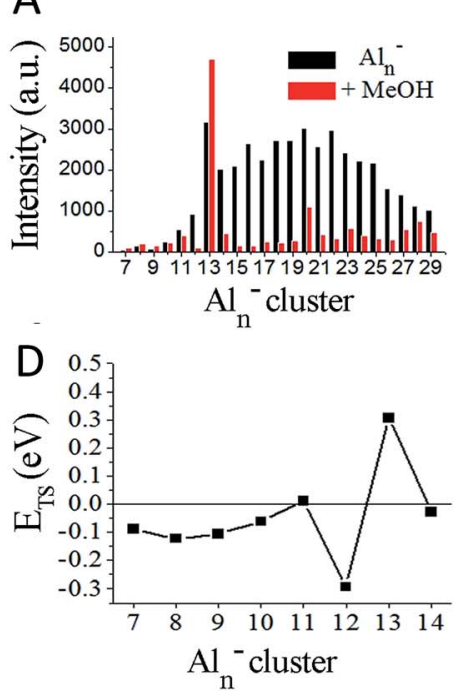

B
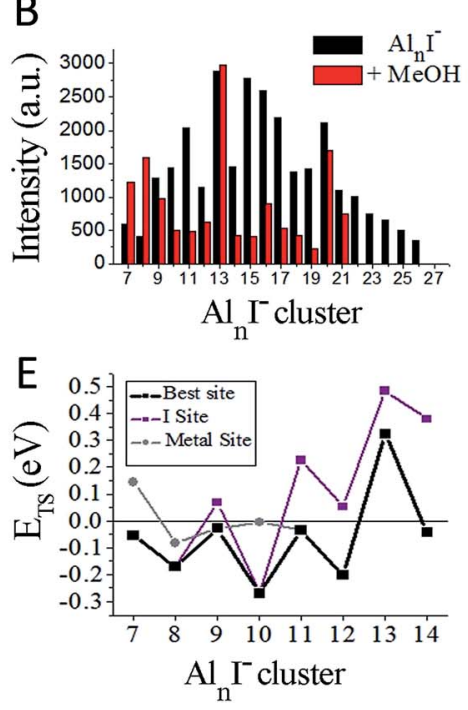

C
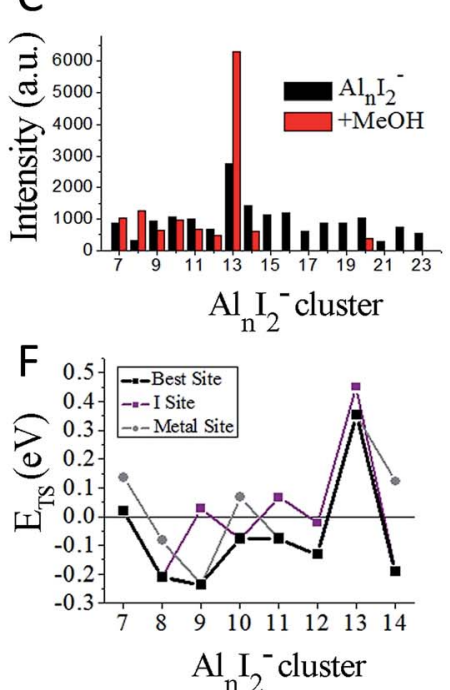

Fig. 2 Ionic intensities and transition state energies $\left(E_{\mathrm{TS}}\right)$. (A-C) The experimental ionic intensities of $\mathrm{Al}_{n}{ }^{-}, \mathrm{Al}_{n} \mathrm{I}^{-}$, and $\mathrm{Al}_{n} \mathrm{I}_{2}^{-}$at the absence and presence of methanol, where the intensity values correspond to the integral areas of the correlated peaks of Fig. 1. (D-F) The calculated $E_{\mathrm{TS}}$ for the cleavage of the $\mathrm{O}-\mathrm{H}$ bond of methanol for $\mathrm{Al}_{n}{ }^{-}, \mathrm{Al}_{n}{ }^{-}$, and $\mathrm{Al}_{n} \mathrm{I}_{2}^{-}$. The structures and energetics are shown in Fig. S10-S37. $\uparrow$ a.u. $=$ arbitrary units.

desorption is the lower energy pathway, then $\mathrm{O}-\mathrm{H}$ cleavage is unlikely.

We have plotted the lowest energy transition states for each cluster under two separate circumstances: when the oxygen of the methanol attaches to an unligated aluminium-aluminium site, and when the oxygen of the methanol attaches to a site corresponding to an aluminium atom that is bound to iodine. We find that $\mathrm{Al}_{11}{ }^{-}$and $\mathrm{Al}_{13}{ }^{-}$have positive $E_{\mathrm{TS}}$ values, which is consistent with the experimental finding that $\mathrm{Al}_{13}{ }^{-}$increases in intensity and $\mathrm{Al}_{11}{ }^{-}$shows resistance to reaction. The remaining clusters $n=7-14$ all show minimal abundance after methanol etching. For the $\mathrm{Al}_{n} \mathrm{I}^{-}$series in Fig. $2 \mathrm{~B}$ and $\mathrm{E}$, we find only $\mathrm{Al}_{13} \mathrm{I}^{-}$ to have a positive $E_{\mathrm{TS}}$, and $\mathrm{Al}_{13} \mathrm{I}^{-}$is experimentally the most abundant species in the series. The binding energies of methanol are shown in Fig. S8. $\dagger$ The experiment also finds $\mathrm{Al}_{7} \mathrm{I}^{-}$and $\mathrm{Al}_{8} \mathrm{I}^{-}$to have increased abundance, while theory finds them to be reactive indicating that these clusters are likely products of fragmentation of larger clusters. For the $\mathrm{Al}_{n} \mathrm{I}_{2}{ }^{-}$series in Fig. $2 \mathrm{C}$ and $\mathrm{F}$, theory finds that $\mathrm{Al}_{7} \mathrm{I}_{2}{ }^{-}$, and $\mathrm{Al}_{13} \mathrm{I}_{2}{ }^{-}$have positive $E_{\mathrm{TS}}$, which is consistent with the experimental results by noting that $\mathrm{Al}_{13} \mathrm{I}_{2}{ }^{-}$is by far the most abundant cluster in this series while $\mathrm{Al}_{7} \mathrm{I}_{2}{ }^{-}$is the third most abundant.

We first examine the reactivity of the $\mathrm{Al}_{13} \mathrm{I}_{m}{ }^{-}$superatomic clusters with methanol. Fig. 3A shows the reaction pathway for $\mathrm{Al}_{13}{ }^{-}$with methanol. $\mathrm{Al}_{13}{ }^{-}$has a closed electronic shell and an icosahedral geometric structure. The LUMO orbitals are plotted in blue, and the HOMO orbitals are plotted in red. The closed electronic shell demonstrates that the frontier orbitals are evenly distributed over the surface of the cluster, precluding the presence of active sites. The oxygen atom of methanol does not readily bind to the cluster, demonstrating that $\mathrm{Al}_{13}{ }^{-}$is not a good Lewis acid. The non-dissociative binding energy of methanol is only $0.23 \mathrm{eV}$, and the $\mathrm{O}$ atom prefers not to bind to the aluminium cluster. The $E_{\mathrm{Ts}}$ of $\mathrm{Al}_{13}{ }^{-}$is $0.31 \mathrm{eV}$ indicating that this cluster is resistant to etching. The addition of iodine results in $\mathrm{Al}_{13} \mathrm{I}^{-}$having a Lewis base site on the opposite side of the cluster as the iodine ligand site, while the LUMO density is evenly distributed over the surface of the metal cluster. The $E_{\mathrm{TS}}$ of $\mathrm{Al}_{13} \mathrm{I}^{-}$is $0.32 \mathrm{eV}$, indicating that $\mathrm{Al}_{13} \mathrm{I}^{-}$will also be resistant to methanol etching. When we investigate the cleavage of the $\mathrm{O}-\mathrm{H}$ bond at the iodine site, we find that the $E_{\mathrm{TS}}$ of $\mathrm{Al}_{13} \mathrm{I}^{-}$increases to $0.49 \mathrm{eV}$. Thus, iodine fails to activate the $\mathrm{Al}_{13}{ }^{-}$cluster. The reason for this is that the Lewis acidity of the $\mathrm{Al}_{13} \mathrm{I}^{-}$cluster is still poor because the induced active site is half filled and cannot serve as a Lewis acid, which accepts an electron pair. This weak Lewis acidity is indicated by the weak non-dissociative binding of methanol of only $0.16 \mathrm{eV}$.

The reaction pathway of $\mathrm{Al}_{13} \mathrm{I}_{2}{ }^{-}$is shown in Fig. 3C, and the $E_{\mathrm{TS}}$ is $0.35 \mathrm{eV}$. The two iodine atoms lie on opposite sides of the cluster, quenching each other's induced active sites. $\mathrm{Al}_{13} \mathrm{I}_{2}{ }^{-}$ remains a poor Lewis acid, with the LUMO charge density evenly distributed over the icosahedral core of the cluster, and the binding energy being only $0.17 \mathrm{eV} . \mathrm{Al}_{13} \mathrm{I}_{3}{ }^{-}$has an $E_{\mathrm{TS}}$ of $0.30 \mathrm{eV}$, and the lowest energy transition state lies at the metal site, with $\mathrm{O}$ binding to the induced active site, and the $\mathrm{H}$ atom binding to the $\mathrm{HOMO}-1$. The addition of iodine to $\mathrm{Al}_{13}{ }^{-}$maintains the pure cluster's resistance to reaction with methanol because the cluster remains a poor Lewis acid due to its closed geometric shell. The high abundance of the $\mathrm{Al}_{13} \mathrm{I}^{-}$, and $\mathrm{Al}_{13} \mathrm{I}_{2}{ }^{-}$in the experiment after exposure to methanol confirms this hypothesis.

The reaction pathway of $\mathrm{Al}_{14}{ }^{-}$with methanol is shown in Fig. 3E. This cluster has a 13-atom icosahedral structure with the $14^{\text {th }}$ atom attached as an adatom. The adatom induces a Lewis acid/base pair on the opposite side of the adatom, and the lowest energy transition state is found at this site. The $E_{\mathrm{TS}}$ is 

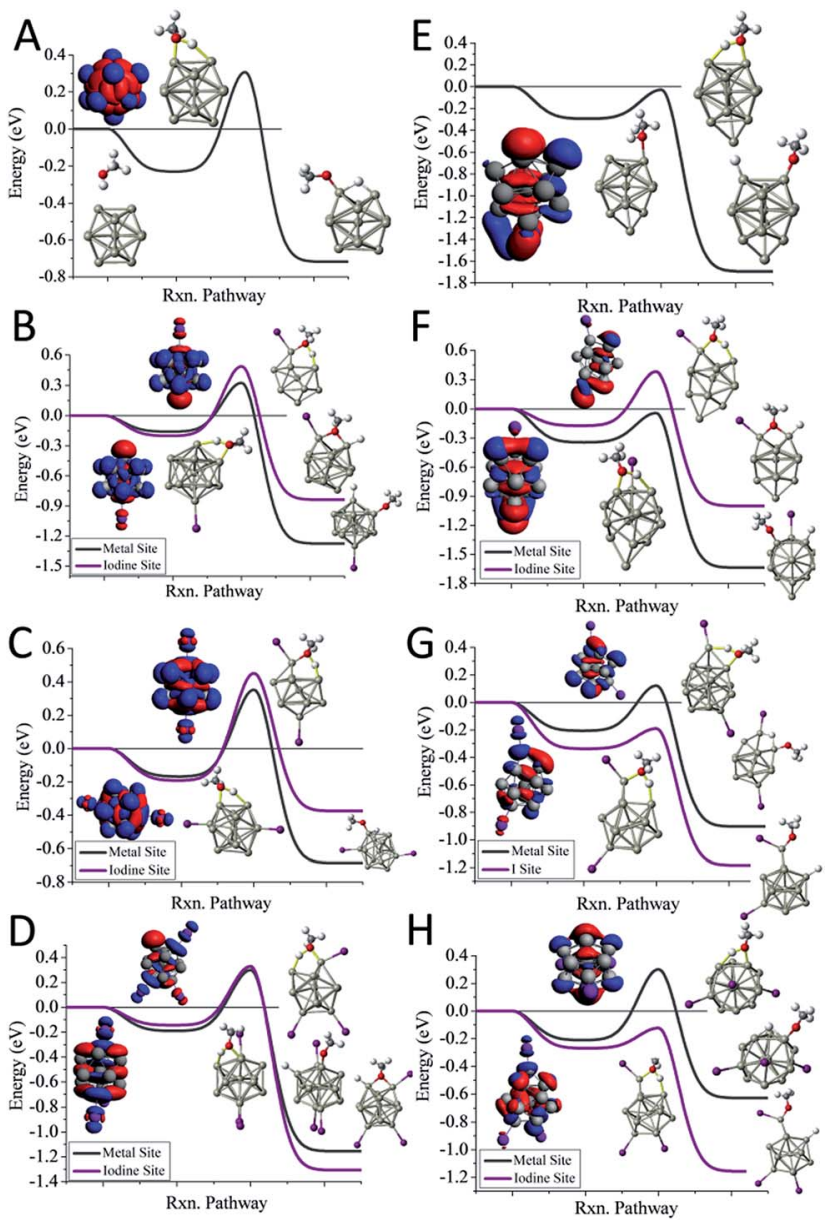

Fig. 3 The reaction coordinates for $\mathrm{Al}_{13} \mathrm{I}_{0-3}{ }^{-}$and $\mathrm{Al}_{14} \mathrm{I}_{0-3}{ }^{-}$. The reaction pathways with $\mathrm{MeOH}$ for (A) $\mathrm{Al}_{13}{ }^{-}$, (B) $\mathrm{Al}_{13} \mathrm{I}^{-}$, (C) $\mathrm{Al}_{13} \mathrm{l}_{2}^{-}$, (D) $\mathrm{Al}_{13} \mathrm{I}_{3}^{-}$, (E) $\mathrm{Al}_{14}^{-}$, (F) $\mathrm{Al}_{14} \mathrm{I}^{-}$, (G) $\mathrm{Al}_{14} \mathrm{I}_{2}^{-}$, (H) $\mathrm{Al}_{14} \mathrm{I}_{3}{ }^{-}$. The red indicates the HOMO or near HOMO orbitals for degenerate orbitals, and blue indicates LUMO or LUMO+1 orbitals that are fully unoccupied.

found to be $-0.03 \mathrm{eV}$, indicating that the cluster is reactive. The non-dissociated methanol binding energy is $0.30 \mathrm{eV}$, implying that the cluster's Lewis acid strength is typical for an aluminium cluster anion. The reaction coordinate for $\mathrm{Al}_{14} \mathrm{I}^{-}$with methanol is shown in Fig. 3F. The $\mathrm{Al}_{14}$ core of $\mathrm{Al}_{14} \mathrm{I}^{-}$has a similar structure to pure $\mathrm{Al}_{14}{ }^{-}$, and the iodine atom is bound opposite site to the adatom. The frontier orbitals reveal a Lewis acid/base complementary active site adjacent to the iodine atom on the cluster. The lowest energy transition state is located at the complementary active site, and $E_{\mathrm{TS}}$ is $-0.04 \mathrm{eV}$, implying a fast reaction with methanol, and the methanol binding energy is $0.34 \mathrm{eV}$, suggesting that the addition of iodine makes the cluster a marginally better Lewis acid than $\mathrm{Al}_{14}{ }^{-}$. The lowest energy transition state at the icosahedral iodine site is found to be unreactive, with a transition state energy of $+0.38 \mathrm{eV}$ greater than the reactants. $\mathrm{Al}_{14} \mathrm{I}_{2}{ }^{-}$has a metallic core with a 13 atom icosahedron and an adatom, with one iodine bound to the adatom and another to an $\mathrm{Al}$ atom on the opposite side of the cluster. The $E_{\mathrm{TS}}$ at the iodine site is $-0.19 \mathrm{eV}$, indicating that the cluster reacts rapidly (Fig. 3G). The lowest energy transition state at the metal site is $+0.12 \mathrm{eV}$, suggesting that the cluster will only react at the adatom iodine site. The electronic structure reveals that LUMO+3 orbital, that lies $0.53 \mathrm{eV}$ above the LUMO, is localized on the adatom and is the orbital that serves as a Lewis acid site. $\mathrm{Al}_{14} \mathrm{I}_{3}{ }^{-}$has a similar geometry as $\mathrm{Al}_{14} \mathrm{I}_{2}{ }^{-}$, with the third iodine atom added at a second icosahedral aluminium atom opposite the adatom. The $E_{\mathrm{TS}}$ at the iodine site is -0.12 $\mathrm{eV}$, indicating that the cluster should react rapidly with methanol (Fig. $3 \mathrm{H}$ ). The $E_{\mathrm{TS}}$ at the metal site is $+0.30 \mathrm{eV}$, revealing that $\mathrm{Al}_{14} \mathrm{I}_{3}{ }^{-}$will react rapidly only at the adatom site. The methanol will react rapidly at the ligand activated adatom sites of $\mathrm{Al}_{14} \mathrm{I}_{2}{ }^{-}$and $\mathrm{Al}_{14} \mathrm{I}_{3}{ }^{-}$while being slow to react at the metal sites, which is confirmed by the nearly complete etching of $\mathrm{Al}_{14} \mathrm{I}_{2}{ }^{-}$ and $\mathrm{Al}_{14} \mathrm{I}_{3}{ }^{-}$in the experimental spectra.

To understand whether the addition of iodine can passivate a cluster as it gains a closed electronic shell, we investigate the $\mathrm{Al}_{7} \mathrm{I}_{0-2}{ }^{-}$clusters. $\mathrm{Al}_{7}{ }^{-}$reacts readily with methanol in experiments, and has an $E_{\mathrm{TS}}$ of $-0.09 \mathrm{eV}$ as shown in Fig. $4 \mathrm{~A}$. The structure of $\mathrm{Al}_{7}^{-}$is an octahedron with an adatom. The frontier orbitals indicate that the $\mathrm{Al}$ atoms on the opposite side of the adatom may serve as complementary active sites. In $\mathrm{Al}_{7} \mathrm{I}^{-}$the iodine atom adds to the $\mathrm{Al}$ adatom site, and the resulting activated adatom has a transition state energy of $-0.05 \mathrm{eV}$, indicating that the cluster should react with methanol, as shown in Fig. 4B. The metal site has a low energy transition state of +0.14 $\mathrm{eV}$, suggesting that the addition of iodine has passivated the cluster's metallic core.

$\mathrm{Al}_{7} \mathrm{I}_{2}{ }^{-}$is passivated with respect to methanol etching, with two iodine atoms on opposite sides of the cluster. The $E_{\mathrm{TS}}$ at the iodine site is $+0.02 \mathrm{eV}$, greater than the energy of the reactants (Fig. 4C). The transition state at the most reactive metal site is $+0.13 \mathrm{eV}$ indicating that the metal core is also passivated. The $\mathrm{Al}_{7} \mathrm{I}_{2}{ }^{-}$cluster still maintains its adatom-like geometry, however the addition of a second iodine ligand to balance out the first ligand increases the energy of the orbital localized on the adatom site, allowing this cluster to be less reactive. The relatively large abundance of $\mathrm{Al}_{7} \mathrm{I}_{2}{ }^{-}$, paired with the low abundance of $\mathrm{Al}_{7}{ }^{-}$after methanol etching confirms our analysis.

One of the puzzles of the experimental mass spectra is the relatively large abundance of $\mathrm{Al}_{9} \mathrm{I}_{3}{ }^{-}$after methanol etching. Our investigations lead to 3 isomers, a ground state structure, and two structures with different iodine positions that are $0.03 \mathrm{eV}$ and $0.06 \mathrm{eV}$ higher in energy. As shown in Fig. 5, we have also investigated the reaction pathway of the three lowest energy isomers of $\mathrm{Al}_{9} \mathrm{I}_{3}{ }^{-}$. The lowest energy structure of $\mathrm{Al}_{9} \mathrm{I}_{3}{ }^{-}$, isomer A in Fig. 5, has two adjacent iodine atoms located on the octahedral core, and a third located perpendicular to the first two iodines. A Lewis acid site is found on the opposite side of the cluster as the third iodine atom, and the $E_{\mathrm{TS}}$ is $-0.16 \mathrm{eV}$, showing that with unbalanced iodine atoms, the cluster is reactive. A second isomer, B in Fig. 5, has balanced ligands and lies $0.03 \mathrm{eV}$ higher in energy than the ground state isomer. With the balanced ligands, the transition state for the $\mathrm{O}-\mathrm{H}$ bond cleavage is only $-0.02 \mathrm{eV}$, less than the energy of the reactants. This transition state is relatively high in energy making it likely to show some resistance to methanol etching. The relatively high abundance of the $\mathrm{Al}_{9} \mathrm{I}_{3}{ }^{-}$cluster is due to this isomer having some resistance to methanol etching. A third isomer $\mathrm{C}$ 

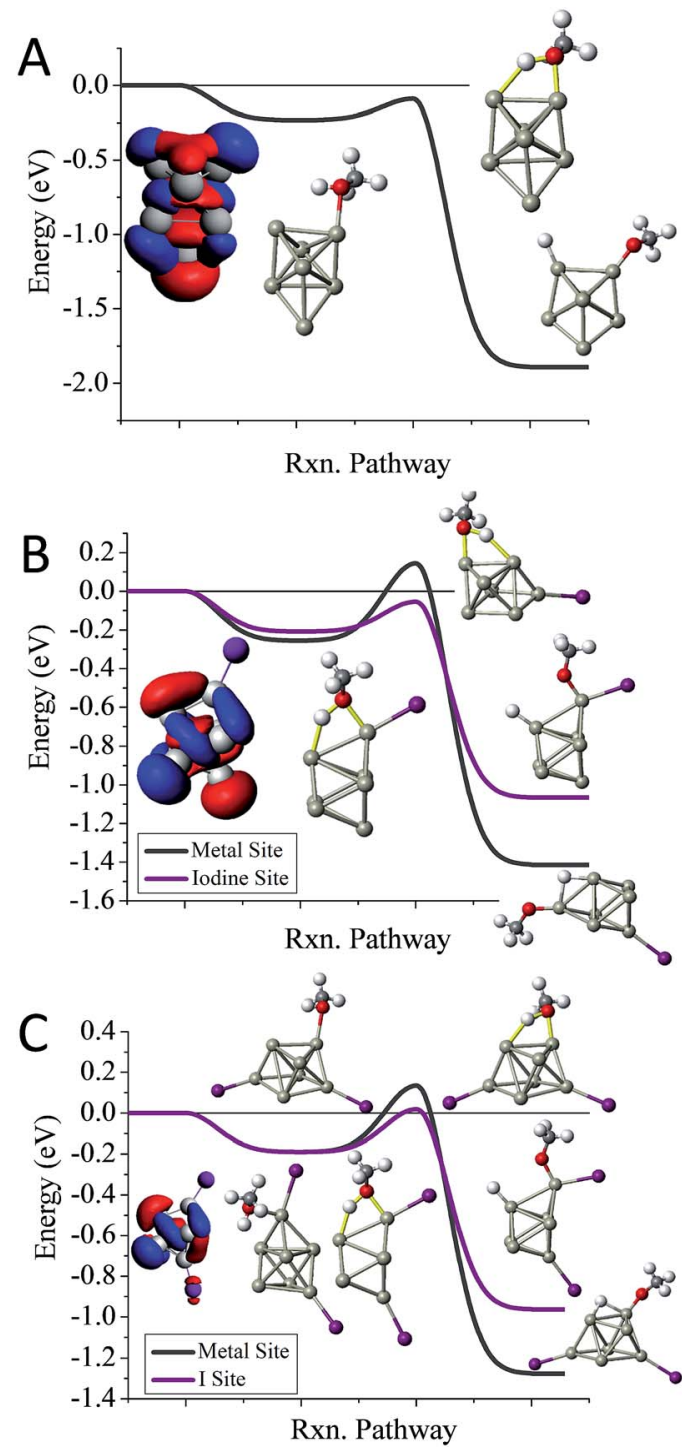

Fig. 4 The reaction coordinates for $\mathrm{Al}_{7} \mathrm{O}_{\mathrm{O}_{2}}{ }^{-}$with $\mathrm{MeOH}$. The calculated reaction pathways for (A) $\mathrm{Al}_{7}^{-}$, (B) $\mathrm{Al}_{7} \mathrm{I}^{-}$, and (C) $\mathrm{Al}_{7} \mathrm{l}_{2}^{-}$with $\mathrm{MeOH}$. The red indicates the $\mathrm{HOMO}$ or near $\mathrm{HOMO}$ orbitals for degenerate orbitals, and blue indicates LUMO or LUMO+1 orbitals that are fully unoccupied. Rxn pathway is abbreviated for cluster reaction coordinate and pathway.

possesses unbalanced ligands and has a transition state energy of $-0.03 \mathrm{eV}$. This may also contribute to the observed abundance. All three isomers contain isostructural metallic cores; however, variations in the precise positioning of the iodine ligand can result in dramatic variations of cluster reactivity.

In addition, we discuss the fragmentation channels of $\mathrm{Al}_{n} l_{m}{ }^{-}$ after methanol etching. Experimentally, we see three prominent features, (i) a decrease in the size distribution of the clusters, (ii) the abundance of $\mathrm{I}^{-}, \mathrm{I}_{3}{ }^{-}, \mathrm{I}_{5}{ }^{-}$, and $\mathrm{AlI}_{4}{ }^{-}$all dramatically increase after the methanol etching, and (iii) there is little abundance of aluminium clusters with methoxy, $\mathrm{Al}_{n} \mathrm{OCH}_{3}{ }^{-}$. The calculated energies are shown in Fig. S9 (ESI $†$ ) in which positive energies correspond to an endothermic reaction, and negative energies correspond to an exothermic reaction. For $\mathrm{Al}_{n}{ }^{-}$, the loss of $\mathrm{AlOCH}_{3}$, as seen in eqn (2), is the most favourable pathway.

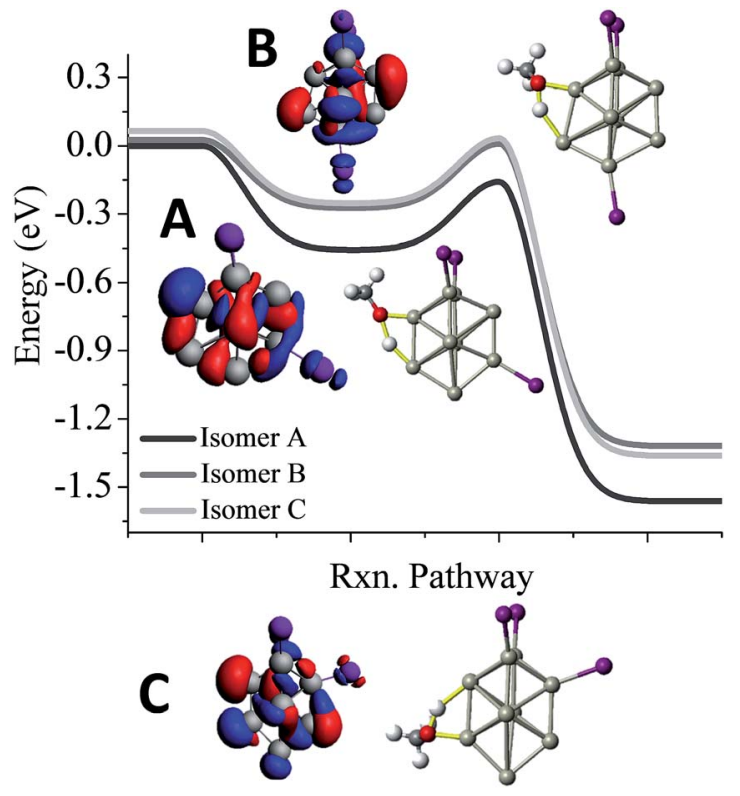

Fig. $5 \mathrm{Al}_{9} \mathrm{I}_{3}^{-}$reactivity. Reaction pathway for the three lowest energy isomers of $\mathrm{Al}_{9} \mathrm{I}_{3}^{-}(\mathrm{A}-\mathrm{C})$. The red indicates the $\mathrm{HOMO}$, and the blue indicates LUMO+1. Rxn pathway is abbreviated for cluster reaction coordinate and pathway.

$$
\mathrm{Al}_{n}{ }^{-}+\mathrm{CH}_{3} \mathrm{OH} \rightarrow \mathrm{Al}_{n-1} \mathrm{H}^{-}+\mathrm{AlOCH}_{3}
$$

This suggests that the product after methanol etching may be $\mathrm{HAl}_{n}{ }^{-}$. For $\mathrm{Al}_{n} \mathrm{I}_{m}{ }^{-}$, the loss of $\mathrm{I}^{-}$is a likely channel, and will produce a neutral cluster with a methoxy so it is not seen in the mass spectra.

$$
\mathrm{Al}_{n} \mathrm{I}_{m}{ }^{-}+\mathrm{CH}_{3} \mathrm{OH} \rightarrow \mathrm{HAl}_{n} \mathrm{I}_{m-1} \mathrm{OCH}_{3}+\mathrm{I}^{-}
$$

The $\mathrm{I}^{-}$loss is endothermic for the addition of a single methanol, however, our previous studies indicated that up to 4 methanol molecules could attach to an aluminium cluster which would generate enough energy to neutralize the cluster and release $\mathrm{I}^{-} .^{27}$ This $\mathrm{I}^{-}$production is the origin of the $\mathrm{I}_{3}{ }^{-}, \mathrm{I}_{5}{ }^{-}$, and $\mathrm{AlI}_{4}{ }^{-}$peaks that are prominent in the etching spectra.

\section{Conclusions}

The addition of iodine ligands to aluminium superatoms may activate or passivate a cluster. To minimize the reactivity of a ligand-protected cluster, the metallic core should have a closed geometric shell with an even distribution of charges around the surface. Secondly, the ligands are most passivating when they are located in a balanced position on opposite sides of the metallic core. $\mathrm{Al}_{14} \mathrm{I}_{3}{ }^{-}$is found to have a closed electronic shell, however because the metallic core has an adatom site with an iodine atom, the cluster is activated with respect to methanol. $\mathrm{Al}_{13} \mathrm{I}_{2}{ }^{-}$has an icosahedral core with no adatom and balanced ligands, and is passivated to methanol. The position of the iodine may induce an active site on the opposite side of the cluster; $\mathrm{Al}_{9} \mathrm{I}_{3}{ }^{-}$is reactive when the iodine atoms are unbalanced, however when the three iodine atoms are balanced 
on opposite sides of the cluster, the cluster is passivated. Our work demonstrates that structural features are just as important as electronic shell closure, or even more important when the synthesis is done in an oxygen-free environment. To highlight this point, $\mathrm{Al}_{50} \mathrm{Cp}_{12}$ is a prominent example of a cluster that is remarkably stable under an inert atmosphere and can be isolated as atomic-precise clusters. This cluster has the hallmarks of stability with a spherical metallic core and balanced ligands. However, the HOMO-LUMO gap of this cluster is only $0.85 \mathrm{eV}$, and so it is quite reactive when exposed to $\mathrm{O}_{2} \cdot{ }^{51}$ This work demonstrates that even if a cluster is protected by ligands, the cluster could be reactive when the geometric considerations are not met, revealing the dual roles of electronic structure and geometric structure on the stability of bare and ligand-protected nanoparticles.

\section{Acknowledgements}

We thank the financial support from CAS of China with Grant No. Y31M0112C1, and the Young Professionals Programme in Institute of Chemistry, Chinese Academy of Sciences (ICCASY3297B1261). The theoretical work (A. C. R., W. H. B., and S. N. K.) was supported by a funding from the Office of Naval Research through grant N00014-12-1-0541.

\section{Notes and references}

1 A. W. Castleman Jr and S. N. Khanna, J. Phys. Chem. C, 2009, 113, 2664-2675.

2 M. V. Kovalenko, L. Manna, A. Cabot, Z. Hens, D. V. Talapin, C. R. Kagan, V. I. Klimov, A. L. Rogach, P. Reiss, D. J. Milliron, P. Guyot-Sionnnest, G. Konstantatos, W. J. Parak, T. Hyeon, B. A. Korgel, C. B. Murray and W. Heiss, ACS Nano, 2015, 9, 1012-1057.

3 W. D. Knight, K. Clemenger, W. A. de Heer, W. A. Saunders, M. Y. Chou and M. L. Cohen, Phys. Rev. Lett., 1984, 52, 21412143.

4 W. A. de Heer, P. Milani and A. Chtelain, Phys. Rev. Lett., 1989, 63, 2834-2836.

5 S. N. Khanna and P. Jena, Phys. Rev. B: Condens. Matter, 1995, 51, 13705-13716.

6 C. Bartels, C. Hock, J. Huwer, R. Kuhnen, J. Schwöbel and B. von Issendorff, Science, 2009, 323, 1323-1327.

7 X. Li, H. Wu, X.-B. Wang and L.-S. Wang, Phys. Rev. Lett., 1998, 81, 1909-1912.

8 P. Andre Clayborne, O. Lopez-Acevedo, R. L. Whetten, H. Grönbeck and H. Häkkinen, J. Chem. Phys., 2011, 135, 094701.

9 O. Lopez-Acevedo, P. A. Clayborne and H. Häkkinen, Phys. Rev. B: Condens. Matter Mater. Phys., 2011, 84, 035434.

10 R. E. Leuchtner, A. C. Harms and A. W. Castleman Jr, J. Chem. Phys., 1989, 91, 2753-2754.

11 R. E. Leuchtner, A. C. Harms and A. W. Castleman Jr, J. Chem. Phys., 1991, 94, 1093-1101.

12 S. A. Ruatta and S. L. Anderson, J. Chem. Phys., 1988, 89, 273286.
13 Z. Luo, C. J. Grover, A. C. Reber, S. N. Khanna and A. W. Castleman Jr, J. Am. Chem. Soc., 2013, 135, 4307-4313. 14 Z. Luo, G. U. Gamboa, J. C. Smith, A. C. Reber, J. U. Reveles, S. N. Khanna and A. W. Castleman Jr, J. Am. Chem. Soc., 2012, 134, 18973-18978.

15 A. C. Reber, S. N. Khanna, P. J. Roach, W. H. Woodward and A. W. Castleman, J. Am. Chem. Soc., 2007, 129, 16098-16101. 16 R. Burgert, H. Schnöckel, A. Grubisic, X. Li, S. T. Stokes, K. H. Bowen, G. F. Ganteför, B. Kiran and P. Jena, Science, 2008, 319, 438-442.

17 P. J. Roach, W. H. Woodward, A. C. Reber, S. N. Khanna and A. W. Castleman, Phys. Rev. B: Condens. Matter Mater. Phys., 2010, 81, 195404.

18 P. J. Roach, A. C. Reber, W. H. Woodward, S. N. Khanna and A. W. Castleman, Proc. Natl. Acad. Sci. U. S. A., 2007, 104, 14565-14569.

19 J. U. Reveles, S. N. Khanna, P. J. Roach and A. W. Castleman, Proc. Natl. Acad. Sci. U. S. A., 2006, 103, 18405-18410.

20 J. C. Smith, A. C. Reber, S. N. Khanna and A. W. Castleman, J. Phys. Chem. A, 2014, 118, 8485-8492.

21 Z. Luo and A. W. Castleman Jr, Acc. Chem. Res., 2014, 47, 2931-2940.

22 D. E. Bergeron, A. W. Castleman, T. Morisato and S. N. Khanna, Science, 2004, 304, 84-87.

23 D. E. Bergeron, P. J. Roach, A. W. Castleman Jr, N. Jones and S. N. Khanna, Science, 2005, 307, 231-235.

24 K. Shimamura, F. Shimojo, R. K. Kalia, A. Nakano, K.-i. Nomura and P. Vashishta, Nano Lett., 2014, 14, 4090-4096.

25 P. J. Roach, W. H. Woodward, A. W. Castleman Jr, A. C. Reber and S. N. Khanna, Science, 2009, 323, 492-495.

26 A. C. Reber, S. N. Khanna, P. J. Roach, W. H. Woodward and A. W. Castleman, J. Phys. Chem. A, 2010, 114, 6071-6081.

27 A. C. Reber, P. J. Roach, W. H. Woodward, S. N. Khanna and A. W. Castleman Jr, J. Phys. Chem. A, 2012, 116, 8085-8091.

28 M. B. Abreu, C. Powell, A. C. Reber and S. N. Khanna, J. Am. Chem. Soc., 2012, 134, 20507-20512.

29 W. H. Woodward, A. C. Reber, J. C. Smith, S. N. Khanna and A. W. Castleman Jr, J. Phys. Chem. C, 2013, 117, 7445-7450.

30 Z. Luo, J. C. Smith, C. Berkdemir and A. W. Castleman Jr, Chem. Phys. Lett., 2013, 590, 63-68.

31 D. M. Cox, D. J. Trevor, R. L. Whetten and A. Kaldor, J. Phys. Chem., 1988, 92, 421-429.

32 F. Shimojo, S. Ohmura, R. K. Kalia, A. Nakano and P. Vashishta, Phys. Rev. Lett., 2010, 104, 126102.

33 M. Walter, J. Akola, O. Lopez-Acevedo, P. D. Jadzinsky, G. Calero, C. J. Ackerson, R. L. Whetten, H. Grönbeck and H. Häkkinen, Proc. Natl. Acad. Sci. U. S. A., 2008, 105, 9157-9162.

34 P. D. Jadzinsky, G. Calero, C. J. Ackerson, D. A. Bushnell and R. D. Kornberg, Science, 2007, 318, 430-433.

35 M. W. Heaven, A. Dass, P. S. White, K. M. Holt and R. W. Murray, J. Am. Chem. Soc., 2008, 130, 3754-3755.

36 M. Zhu, C. M. Aikens, F. J. Hollander, G. C. Schatz and R. Jin, J. Am. Chem. Soc., 2008, 130, 5883-5885.

37 H. Häkkinen, Chem. Soc. Rev., 2008, 37, 1847-1859.

38 X. Liu, Y. Wu, S. Li, Y. Zhao, C. Yuan, M. Jia, Z. Luo, H. Fu and J. Yao, RSC Adv., 2015, 5, 30610-30616. 
39 S. Malola and H. Häkkinen, J. Phys. Chem. Lett., 2011, 23162321.

40 A. Dass, J. Am. Chem. Soc., 2009, 131, 11666-11667.

41 H. Yang, Y. Wang, H. Huang, L. Gell, L. Lehtovaara, S. Malola, H. Häkkinen and N. Zheng, Nat. Commun., 2013, 4, 3422.

42 M. F. Bertino, Z.-M. Sun, R. Zhang and L.-S. Wang, J. Phys. Chem. B, 2006, 110, 21416-21418.

43 Y. Negishi, K. Nobusada and T. Tsukuda, J. Am. Chem. Soc., 2005, 127, 5261-5270.

44 K.-W. Klinkhammer, W. Uhl, J. Wagner and W. Hiller, Angew. Chem., Int. Ed. Engl., 1991, 30, 179-180.

45 P. Henke, N. Trapp, C. E. Anson and H. Schnöckel, Angew. Chem., Int. Ed., 2010, 49, 3146-3150.
46 A. Ecker, E. Weckert and H. Schnockel, Nature, 1997, 387, 379-381.

47 H. Schnöckel, Chem. Rev., 2010, 110, 4125-4163.

48 M. Neumaier, M. Olzmann, B. Kiran, K. H. Bowen, B. Eichhorn, S. T. Stokes, A. Buonaugurio, R. Burgert and H. Schnöckel, J. Am. Chem. Soc., 2014, 136, 3607-3616.

49 G. te Velde, F. M. Bickelhaupt, E. J. Baerends, C. Fonseca Guerra, S. J. A. van Gisbergen, J. G. Snijders and T. Ziegler, J. Comput. Chem., 2001, 22, 931-967.

50 J. P. Perdew, K. Burke and M. Ernzerhof, Phys. Rev. Lett., 1996, 77, 3865-3868.

51 P. A. Clayborne, O. Lopez-Acevedo, R. L. Whetten, H. Grönbeck and H. Häkkinen, Eur. J. Inorg. Chem., 2011, 2649-2652. 